\title{
Quality of Work Life of Public School Nurses in the Philippines
}

\author{
Kaila Mae L. Macairan ${ }^{1}$, Ryan Michael F. Oducado ${ }^{1}$, Mika E. Minsalan $^{1}$, \\ Risa G. Recodo ${ }^{1}$, Gio Franco D. Abellar ${ }^{1}$ \\ ${ }^{1}$ College of Nursing, West Visayas State University, Philippines \\ Corresponding Author: Ryan Michael F. Oducado (rmoducado@wvsu.edu.ph)
}

\begin{abstract}
Background: School nurses play a crucial role in the provision of comprehensive health services to the school population. A balanced quality of work life (QWL) with favorable conditions that support and uphold employee satisfaction is imperative for school nurses to maximize their provision of care for their clientele. Among the many nursing specialties, research among school nurses is not given much attention.

Purpose: This study aimed to determine the QWL of public school nurses in the Philippines.

Methods: This study utilized a descriptive correlational research design with 57 public school nurses as study participants. Self-reported data were gathered utilizing Walton's QWL scale. Data were analyzed using the Mann-Whitney U test, Kruskal-Wallis test, and Spearman-rank correlation coefficient.

Results: Results indicated that public school nurses had high QWL $(M=4.16)$. Among the eight subscales, opportunities at work $(M=4.04)$ and social integration at work $(M=4.03)$ had the lowest mean scores. There were no significant differences in the QWL according to sex $(p=0.929)$, marital status $(p=0.326)$, educational attainment $(p=0.391)$ and length of work experience $(p=0.059)$, while there was a significant relationship between age $(p=0.005)$ and QWL of public school nurses.

Conclusion: Public school nurses generally have a high QWL. Nevertheless, to further improve their QWL, it is recommended that public school nurses must be provided with more chances for continuous professional growth and opportunities for better social integration.
\end{abstract}

Keywords: Nurses; quality of work life; school nurses; work satisfaction

\section{BACKGROUND}

Quality of work life (QWL) refers to the personnel's reaction to work and its essential outcome in relation to job satisfaction and psychological health. This definition of QWL emphasizes personal outcomes, work experiences, and how to improve work to meet the individual needs of employees (Walton, 1973 cited in Kermansaravi, Navidian, Rigi, \& Yaghoubinia, 2015). Improving the QWL is a comprehensive process to improve employees' quality of life at work and is essential in attracting and retaining employees (Saraji \& Dargahi, 2006). 
School nursing is a specialized practice of nursing with the duty to promote student health, development, and academic success (National Association of School Nurses, U.S., 2017). In the Philippines, nurses in public schools are working under the Department of Education. School nurses are the front liners in the delivery of health and nutrition programs in elementary and secondary public schools in the country (National League of Philippine Government Nurses, Inc., 2007).

School nurses are vital support personnel in the school system. This is based on the philosophy that the quality of health of the school population influences students' academic performance and instructional outcomes (National League of Philippine Government Nurses, Inc., 2007). Studies have documented the positive impact of school nursing and considered it as a good investment in improving students' achievement (Maughan, 2018; Stock, Larter, Kieckehefer, Thronson, \& Maire, 2002).

This study tries to look into the QWL of nurses working in the school setting. While the satisfaction and QWL of nurses have been widely explored, there are, however, unique factors that affect the QWL of school nurses. The high student-nurse ratio, administrative support, salary variation, task requirements, and parents and students' concerns are factors that impact school nursing, making it different from other practice areas of nurses (Guenette, 2014). School nurses have a broad and differentiated scope of practice in their field of expertise. Besides, school nurses do not only serve a single individual rather than the school population. The current nurse to student ratio at the Department of Education is 1:5,000 (Philippine Development Institute for Development Studies, 2018).

As school nurses perform their roles often independently in the field and given their large caseloads, high levels of motivation are needed to serve this role (Johnson, 2017; Zborowska-Dulat, Uchmanowicz, Manulik, \& Manulik, 2018). More recently, Senate Bill No. 663 (2016) and House Bill No. 7824 (2018) call to hire one nurse in every public school in the Philippines to ensure students' access to basic health services. Understanding the work conditions of school nurses and their sources of contentment at work are necessary to attract and foster commitment in the field of school nursing.

This study is an open avenue for research about QWL among school nurses in the Philippines wherein there is limited published study related to the topic. Among the many nursing specialties, there is not much focus and attention given to research among school nurses. Thus, the researchers conducted this study to fill the gaps in the literature about the QWL of school nurses.

\section{PURPOSE}

This study was conducted to determine the QWL of public school nurses in the Philippines.

\section{METHODS}

\section{Research design}

A descriptive correlational study was utilized using a one-shot survey design. 


\section{Samples and setting}

The participants were the 57 out of 62 public school nurses of the Schools Division in a province in Western Visayas, Philippines. The overall response rate was $92 \%$ of the total population included in the study. All public school nurses willing to participate in the study were included. The five (5) public school nurses who were not able to participate were either on duty in the field during the conduct of the survey or refused to participate.

\section{Research instrument and data collection}

The researchers used the adapted version of Walton's QWL scale by Timossi, Pedrosso, Francisco, and Pilatti (2008). The scale was composed of a total of 35 items with eight (8) subscales: salary or adequate and fair compensation (4 items), working conditions or the safe and healthy environment (6 items), use of capacities or development of human capacities at work (5 items), opportunities or growth and security at work (4 items), social integration (4 items), constitutionalism or respect to laws at work (4 items), space that work occupy in life or total life space (3 items) and social relevance and importance of work (5 items). To determine the public school nurses' perception of their QWL taking into account their individual needs and aspirations, the participants were asked to answer in a Likert scale polarized in five points with responses ranging from " 1 = very dissatisfied" to "5 = very satisfied". The following interpretation of mean was used: 1.00-1.79 = very low QWL; 1.80-2.59 = low QWL; 2.60-3.39 = moderate QWL; 3.404.19 = high QWL; 4.20-5.00 = very high QWL. The overall instrument has a calculated Cronbach's alpha of 0.96 (Timossi et al., 2008). A personal data sheet was used to collect data about the participants' socio-demographic and work-related profile.

Prior to the actual survey, pertinent permissions to conduct the study were secured from the Division Heads. Majority of data were collected during the monthly assembly of school nurses at the Department of Education Schools Division on September 2018. However, about 15 percent of the participants were not able to answer the survey forms at this time. Survey forms, enclosed in a brown envelope were distributed to those who were not available during the assembly with the assistance of one of the nurses in the Division Office. The participants were given sufficient time to answer the instrument. It took them approximately 10 to 15 minutes to accomplish the survey. Upon retrieval, the survey forms were reviewed for completeness of data entry. This was done to ensure that the results will not have any missing data.

\section{Data analysis}

The following descriptive statistical treatments were employed to analyze and interpret the data: frequency count, percentage, rank, mean, median, and grouped median. MannWhitney $U$ test and Kruskal-Wallis test were performed to determine significant differences and Spearman-rank correlation coefficient was applied to determine significant relationships between variables. Alpha level of significance was set at 0.05. The SPSS software package version 23 was utilized for all statistical data analysis.

\section{Ethical considerations}

The fundamental human rights of the participants, data confidentiality, and anonymity were observed throughout the study. Participants were given full disclosure about the 
research and were given the freedom whether to participate or not in the study. Written informed consent was obtained from each participant to indicate their voluntary participation and involvement in the study. Survey forms were enclosed in a brown envelope, and participants were instructed to seal the envelope before returning the filled in questionnaires. The Declaration of Helsinki (World Medical Association, 2001) and the National Ethical Guidelines for Health and Health-Related Research (Philippine Health Research Ethics Board, 2017) guided the researchers in the ethical conduct of the study.

\section{RESULTS}

\section{Socio-demographic characteristics of the respondents}

Table 1 shows that the median age of the participants was 34 years old. Majority were young adults (56.1\%), females (71.9\%), married (64.9\%) and with a Bachelor's degree (75.4\%). Moreover, the majority worked as a public school nurse for less than 1 year (57.9\%). All public school nurses 57 (100\%) were employed as Nurse II permanent employees with a Salary Grade of 15 . Nurse II is the position title for public school nurses in the Philippine Department of Education School Health and Nutrition Units in the Schools Division with a corresponding compensation of Salary Grade 15.

Table 1. Socio-demographic and work-related characteristics of public school nurses

\begin{tabular}{lll}
\hline Category & $f$ & $\%$ \\
\hline Age (Median=34 years old) & 32 & 56.1 \\
$\quad$ Young Adult (24-35) & 25 & 43.9 \\
$\quad$ Middle to Older Adult (36-63) & 16 & 28.1 \\
Sex & 41 & 71.9 \\
$\quad$ Male & & \\
$\quad$ Female & 20 & 35.1 \\
Marital Status & 37 & 64.9 \\
$\quad$ Single & & \\
$\quad$ Married & 43 & 75.4 \\
Educational Attainment & 14 & 24.6 \\
$\quad$ Bachelor's Degree & & \\
$\quad$ Bachelor's Degree with Master Units/ Master's Degree & 33 & 57.9 \\
Length of Work Experience & 11 & 19.3 \\
$\quad$ Less than 1 year & 13 & 22.8 \\
$\quad$ 1-10 years & & \\
$\quad$ 11 or more years & 57 & 100 \\
Position & & \\
$\quad$ Nurse II & 57 & 100 \\
Employment Status & & \\
$\quad$ Permanent & 57 & 100 \\
Salary Grade & & \\
$\quad$ SG 15 &
\end{tabular}

\section{Level of QWL of public school nurses}

Table 2 shows the QWL of public school nurses. Overall, public school nurses had high QWL $(M=4.16$, Median=4.06). As to each dimension of QWL, public school nurses had very high QWL in terms of space that the work occupies in their life $(M=4.29$, Very 
high, Rank 1), social relevance and importance of their work $(M=4.25$, Vey high, Rank $2.5)$, salary $(M=4.25$, Very High, Rank 2.5), and use of their capacities at work $(M=4.21$, Very High, Rank 4). They had high QWL in the areas of constitutionalism at work ( $\mathrm{M}=4.14$, High, Rank 5), working conditions ( $M=4.11$, High, Rank 6), opportunities at work $(M=4.04$, High, Rank 7$)$ and social integration at work $(M=4.03$, High, Rank 8).

Table 2. Level of QWL of public school nurses

\begin{tabular}{llll}
\hline Dimensions of QWL & Mean & Interpretation & Rank \\
\hline 1. Space that work occupies in the life & 4.29 & Very high & 1 \\
2. Social relevance and importance of work & 4.25 & Very high & 2.5 \\
3. Salary & 4.25 & Very high & 2.5 \\
4. Use of capacities at work & 4.21 & Very high & 4 \\
5. Constitutionalism at work & 4.14 & High & 5 \\
6. Working conditions & 4.11 & High & 6 \\
7. Opportunities at work & 4.04 & High & 7 \\
8. Social integration at work & 4.03 & High & 8 \\
Total Quality of Work Life (Median=4.06) & 4.16 & High & \\
\hline
\end{tabular}

\section{Differences in the QWL of public school nurses}

Table 3 shows the significant differences in the QWL of public school nurses in terms of socio-demographic and work-related characteristics. The results revealed that there were no significant differences in the QWL of public school nurses when classified according to their sex $(p=0.929)$, marital status $(p=0.326)$, educational attainment $(p=0.391)$ and length of work experience $(\mathrm{p}=0.059)$. However, the Mann-Whitney $\mathrm{U}$ test indicated that the QWL of public school nurses was significantly higher for middle to older adults than for young adults $(p=0.005)$.

Table 3. Differences in the QWL according to socio-demographic and work-related characteristics

\begin{tabular}{llll}
\hline Variables & $\begin{array}{l}\text { Grouped } \\
\text { Median }\end{array}$ & & $p$ \\
\hline Age $^{\mathrm{a}}$ (Median=34 years old) & & 227.50 & $0.005^{*}$ \\
$\quad$ Young Adult (24-35) & 4.01 & & \\
$\quad$ Middle to Older Adult (36-63) & 4.22 & 323.00 & 0.929 \\
Sex $^{\mathrm{a}}$ & & & \\
$\quad$ Male & 4.07 & & 0.326 \\
$\quad$ Female & 4.05 & 311.50 & \\
Marital Status & & \\
$\quad$ Single & 4.03 & & 0.391 \\
$\quad$ Married & 4.09 & \multirow{2}{*}{255.00} & \\
Educational Attainment $^{\mathrm{a}}$ & 4.03 & & \\
$\quad$ Bachelor's Degree & 4.17 & & 0.059 \\
$\quad$ Bachelor's Degree with Master Units/ & & \\
$\quad$ Master's Degree & & 5.666 & \\
Length of Work Experience & & \\
$\quad$ Less than 1 year & 4.01 & & \\
\hline
\end{tabular}




\begin{tabular}{llc}
\hline Variables & $\begin{array}{l}\text { Grouped } \\
\text { Median }\end{array}$ & $p$ \\
\hline $1-10$ years & 4.01 & \\
11 or more years & 4.31 & \\
\hline Notes: ${ }^{a}$ Mann-Whitney $U,{ }^{b}$ Kruskal-Wallis, ${ }^{*} p<0.05$ &
\end{tabular}

\section{Correlation between age, length of work experience and QWL}

Table 4 shows the Spearman's rho correlation results for the significant relationship between age and QWL and length of work experience and QWL of public school nurses. Statistical analysis revealed that there was no significant relationship between the length of work experience as a public school nurse and QWL $(p=0.052)$ while there was a significant relationship between age and QWL $(p=0.005)$.

Table 4. Correlation between age, length of work experience and $Q W L$

\begin{tabular}{lll}
\hline QWL & $r$ & $p$ \\
\hline Age & 0.363 & 0.005 \\
Length of Work Experience & 0.258 & 0.052 \\
\hline$* p<0.05$ & &
\end{tabular}

\section{DISCUSSION}

This study investigated the QWL of public school nurses. It was demonstrated in this study that the QWL of public school nurses as a whole was high. This means that public school nurses generally appreciate their job and are contended with the different aspects of their work life. The result of this study is congruent with the findings of some studies in the local setting that investigated the work setting and satisfaction of hospital nurses. Dones, Paguio, Bonito, Balabagno, and Pagsibigan (2016) discovered that although nurses reported the lowest positive responses in physiologic and safety needs, the overall job satisfaction of Filipino nurses was high. Similarly, Lapeña, Tuppal, Loo, and Abe (2017) found that nurses working in a tertiary hospital in Manila, Philippines, had high work satisfaction. However, there were also reports that Filipino nurses were not quiet contended with their work. For instance, Rosales, Labrague, and Rosales (2013) disclosed that staff nurses in Samar, Philippines were slightly unsatisfied with their job.

Public school nurses in the Philippines are not the only school nurses reporting high QWL or satisfaction at work. Previous researches on QWL specific to nurses working in the school setting also support the result of the present study. Nurses working in a public school in the State of Illinois were most satisfied with their professional status and autonomy. Nurses are more satisfied with their job when they believe that they can positively impact students' health (Guenette, 2014). Public school nurses in this study likewise had very high QWL in the aspect of social relevance and use of capacities at work. Use of capacities at work relates to how work provides certain autonomy and how skills and knowledge are being used at work (Timossi et al., 2008; Fernandes, Martins, Caixeta, Costa Filho, Braga, \& Antonialli, 2017). Moreover, a study among Polish school nurses also characterized school nurses having a high level of job satisfaction (Zborowska-Dulat et al., 2018). A much earlier study likewise disclosed that majority of school nurses expressed contentment with their jobs and were satisfied with their 
present positions, although issues related salary, control issues, coping, and role strain were mentioned (Junious, Johnson, Peters, Markham, Kelder, \& Yacoubian, 2004).

Meanwhile, this study also revealed that public school nurses had high QWL in terms of the space that work occupies in their life. This dimension of QWL is directly related to the balance between time devoted to work and personal life or work-life balance (Fernandes et al., 2017; Timossi et al., 2008). School nurse work schedule was identified as a factor influencing school nurses' decision to enter school nursing in a study among school nurses in a large, urban school district in the U.S. (Smith \& Firmin, 2009). Nonetheless, time-workload-caseload was considered a top barrier that impacts school nurses' ability to practice school nursing (Davis, 2018).

In this study, while public school nurses had an overall high QWL, among the eight (8) subscales, they ranked lowest in opportunities provided at work and social integration. Opportunities provided at work relates to opportunities for professional growth, such as participation in trainings and chances for further studies (Timossi et al., 2008). Public school nurses at the Department of Education in the Philippines, however, have limited opportunities for rank promotion. This possibly explains why public school nurses in this study rated aspect of opportunities provided at work of least quality. Moreover, most of the public school nurses in this study only had a Bachelor's degree. School nurses may also desire for further degree advancement and be given more chances to attend seminars and trainings to enhance their competencies.

On the other hand, social integration corresponds to the absence of discrimination at work and focuses on relationship and commitment with colleagues and supervisors (Fernandes et al., 2017; Timossi et al., 2008). Public school nurses are deployed in different public elementary and secondary schools all over the province. Most of the time, they are in the field delivering school-based health services to their clientele. As a result, they may have less time to work closely with their supervisors and fellow public school nurses.

Comparing the findings of this study with the QWL of hospital nurses in other countries or elsewhere, the result of this study is incongruent with most of the findings in the literature. School nurses reported better QWL than hospital nurses. For instance, staff nurses in Egypt had low-level QWL (Morsy \& Sabra, 2015) and nurses in public health facilities in South Ethiopia were dissatisfied with their QWL (Kelbiso, Belay, \& Woldie, 2017). Results of studies in India among nurses in several hospitals (Battu \& Chakravarthy, 2014), in government and private hospitals (Suresh, 2013), in a tertiary care hospital (Hemanathan, Sreelekha, Prakasam, \& Golda, 2017) and in private sectors (Fasla, 2017) revealed a moderate level QWL. Moderate level QWL was also disclosed among nurses in Iran (Moradi, Maghaminejad, \& Azizi-fini, 2012; Nayeri, Salehi, \& Noghabi, 2011) and Bangladesh (Akter, Akkadechanunt, Chontawan, \& Klunklin, 2018). On the contrary, nurses in Latvia described their work life quality as satisfactory (Blumberga \& Olava, 2016) and QWL was at the customary level among nurses in Saudi Arabia (Albaqawi, 2018). This result of the study provides insights that the school work setting is different from the hospital work environment. Public school nurses commonly deal with promotive and preventive aspects of the health of the school 
population while nurses working in the hospital deal with curative components of care and acute cases. Public school nursing is a highly autonomous practice with less direct supervision from physicians. Moreover, public school nurses have regular working hours compared to the shifting work schedule of hospital nurses. Given these variations in the scope of practice and work environment between school nurses and hospital nurses, public school nurses appear to have better QWL.

The results of this present investigation demonstrated that age was significantly related to QWL and that middle to older age public school nurses aged 36 to 63 years old had higher QWL than their younger counterparts. An aspect of QWL, particularly work condition, was similarly found to be associated with age in an earlier study (Albaqawi, 2018). McNeese-Smith and van Servellen (2000) emphasized that mature nurses have better job satisfaction, productivity, and commitment to the organization. In contrast, while age was significantly associated with QWL in the study of Hemanathan et al. (2017), it was shared that the younger age group (21-30) of hospital nurses in India was associated with QWL.

Prior work of scholars conducted elsewhere also disclosed inconsistent findings. One study noted that age and years of experience had no significant relationship with QWL among nurses working in public health facilities in South Ethiopia (Kelbiso et al., 2017). On the other hand, another study disclosed that experience was related to QWL while age was not associated with QWL among hospital nurses in India (Thakre, Thakre, \& Thakre, 2017) and in Iran (Moradi et al., 2012). With these contrasting findings, caution is warranted when interpreting the result of this aspect of the study. It must be noted that the distribution of the participants in this study could be a possible factor why there is a significant difference in age while significant difference cannot be appreciated in length of work experience. More than half of the participants in this study were newly hired, having less than a year of experience as a public school nurse. It was only recently that more permanent positions were opened for public school nurses by the Department of Education. The number of public school nurses needed to serve public schools in the Philippines is expected to rise if Senate Bill No. 663 (2016) and House Bill No. 7824 (2018) will be enacted into law. Cost-benefit study of school nursing services found school nursing to be a cost-beneficial investment of public money (Wang, Vernon-Smiley, Gapinski, Desisto, Maughan, \& Sheetz, 2014). Likewise, the U.S. National Association of School Nurses recommends that students should have access to a full-time baccalaureate-prepared registered nurse (Willgerodt, Brock, \& Maughan, 2018).

This study has its limitations. Further research may be conducted in a larger sample among nurses working in the school setting, including those in the private sector. Moreover, the study may have benefited from additional qualitative investigation to validate the findings of the study. Also, while Walton's QWL scale has been used in studies conducted elsewhere, further validation of the scale is recommended if administered among Filipino nurses. In addition, although a direct comparison of the QWL of nurses in different work settings was not promising, this study provided insights on the possible variations on the QWL between nurses in the hospital and school settings. Nonetheless, this study sheds light on the QWL situation of nurses 
entrusted to promote the health of the school population. This study also provides evidence that can enlighten school leadership and policymakers to devise ways of improving the QWL of school nurses.

\section{CONCLUSION}

Public school nurses have high QWL. Age is a significant factor related to the QWL of public school nurses. The older the nurses, the more they appreciate working in a public school setting. Nevertheless, opportunities at work and social integration are perceived to be of least quality aspects of the public school nurses' work life. Public school nurses must be provided with added opportunities for continuous professional development and be given more chances for better social integration to further improve their QWL.

\section{ACKNOWLEDGMENT}

The authors would like to thank all the public school nurses who participated in this study as well as colleagues in the field of school nursing, Mr. Jofred Martinez and Ms. Aileen Daclis, for reviewing this article before publication.

\section{CONFLICT OF INTEREST}

The authors declare no conflict of interest.

\section{REFERENCES}

Albaqawi, H. (2018). Quality nursing work life among nurses in Hail Region, Kingdom of Saudi Arabia: Redefining boundaries of work and life. Advances in Social Sciences Research Journal, 5(3), 433-439. doi: http://dx.doi.org/10.14738/ assrj.53.4341

Akter, N., Akkadechanunt, T., Chontawan, R., \& Klunklin, A. (2018). Factors predicting quality of work life among nurses in tertiary-level hospitals, Bangladesh. International Nursing Review, 65(2), 182-189. doi: 10.1111/inr.12401.

Battu, N., \& Chakravarthy, G. K. (2014). Quality of work life of nurses and paramedic staff in hospitals. International Journal of Business and Administration Research Review, 2(4), 200-207. Retrieved from http://ijbarr.com/downloads/2014/vol2issue $4 / 25$.pdf

Blumberga, S., \& Olava, S. (2016). Quality of hospital nursing work life, psychological and subjective well-being. Rural Environment Education Personality, 13, 295300. Retrieved from http://llufb.llu.lv/conference/REEP/2016/Latvia-UnivAgricult-REEP-2016proceed2255-808X-295-300.pdf

Davis, D. S. (2018). School nursing practice for the 21st century: Assessing scope of practice in the current workforce (Doctoral Dissertation). Georgetown University, Washington, D.C., USA. Retrieved from https://repository.library.georgetown.edu/bitstream/handle/10822/1053078/Davis_ georgetown_0076D_14118.pdf?sequence=1\&isAllowed=y

Dones, L. B. P., Paguio, J. T., Bonito, S. R., Balabagno, A. O., \& Pagsibigan, J. S. (2016). Work environment of nurses in the Philippines: A preliminary study. Philippine Journal of Nursing, 86(2), 4-10. Retrieved from http://www.pnapjn.com/research/001/ 
Fasla, N. P. (2017). A study on quality of work life among private hospital nurses with special reference to Mannarkkad Municipality, Palakkad District. International Journal of Research-Granthaalayah, 5(4), 129-134. doi: https://doi.org/10.5281/zenodo.569986

Fernandes. R. B., Martins, B. S., Caixeta, R. P. Costa Filho, C. G., Braga, G. A. \& Antonialli, L. M. (2017). Quality of work life: An evaluation of Walton model with analysis of structural equations. Revista Espacios, 38(3). Retrieved from https://www.revistaespacios.com/a17v38n03/a17v38n03p05.pdf

Guenette, M. G. (2014). School nurse job satisfaction, provision of health education, and student attendance (Honors Projects). Illinois Wesleyan University, Bloomington, Illinois, USA. Retrieved from https://digitalcommons.iwu.edu/ cgi/viewcontent.cgi?article=1046\&context=nursing_honproj

Hemanathan, R., Sreelekha, Prakasam, P., \& Golda, M. (2017). Quality of work life among nurses in a tertiary care hospital. JOJ Nursing \& Health Care, 5(4), 1-8. Retrieved from https://juniperpublishers.com/jojnhc/pdf/JOJNHC.MS.ID.555667 .pdf

House Bill No. 7824. (2018). School health and safety act of 2018. Retrieved from https://www.bworldonline.com/house-bill-filed-seeking-to-assign-more-schoolnurses-in-public-schools/

Johnson, K. (2017). Healthy and ready to learn: School nurses improve equity and access. OJIN: The Online Journal of Issues in Nursing, 22(3), Manuscript 1. doi: 10.3912/OJIN.Vol22No03Man01

Junious, D. L., Johnson, R. J., Peters, R. J., Markham, C. M., Kelder, S. H., \& Yacoubian, G. S. (2004). A study of school nurse job satisfaction. The Journal of School Nursing, 20(2), 88-93. doi: 10.1177/10598405040200020601

Kelbiso, L., Belay, A., \& Woldie, M. (2017). Determinants of quality of work life among nurses working in Hawassa town public health facilities, South Ethiopia: A cross-sectional study. Nursing Research and Practice, Article ID 5181676. doi: https://doi.org/10.1155/2017/5181676

Kermansaravi, F., Navidian, A., Rigi, S. N., \& Yaghoubinia, F. (2015). The relationship between quality of work life and job satisfaction of faculty members in Zahedan University of Medical Sciences. Global Journal of Health Science, 7(2), 228-234. doi: $10.5539 /$ gjhs.v7n2p228

Lapeña, L. F. R., Tuppal, C. P., Loo, B. G. L, \& Abe, K. H. C. (2017). Transformational and transactional leadership styles of nurse managers and job satisfaction among Filipino nurses: A pilot study. Nurse Media Journal of Nursing, 7(2), 65-78. doi: 10.14710/nmjn.v7i2.15171

Maughan, E. D. (2018). School nurses: An investment in student achievement. Phi Delta Kappan. Retrieved from https://www.kappanonline.org/maughan-schoolnurses-investment-student-achievement/

McNeese-Smith, D., \& van Servellen, G. (2000). Age, developmental, and job stage influences on nurse outcomes. Outcomes Management for Nursing Practice, 4(2), 97-104. Retrieved from https://www.ncbi.nlm.nih.gov/pubmed/11111591

Moradi, T., Maghaminejad, F., \& Azizi-fini, I. (2014). Quality of working life of nurses and its related factors. Nursing and Midwifery Studies, 3(2), e19450. Retrieved from https://www.ncbi.nlm.nih.gov/pmc/articles/PMC4228533/ 
Morsy, S. M., \& Sabra, H. E. (2015). Relation between quality of work life and nurses job satisfaction at Assiut university hospitals. Al-Azhar Assiut Medical Journal, 13(1), 163-171. Retrieved from http://www.aamj.eg.net/journals/pdf/2346.pdf

National Association of School Nurses (U.S.). (2017). Definition of school nursing. Retrieved from https://www.nasn.org/about-nasn/about

National League of Philippine Government Nurses, Inc., (2007). Public health nursing in the Philippines. 10th ed. Manila: Philippines.

Nayeri, N. D., Salehi, T., \& Noghabi, A. A. (2011). Quality of work life and productivity among Iranian nurses. Contemporary Nurse, 39(1), 106-118. doi: 10.5172/conu.2011.39.1.106.

Philippine Development Institute for Development Studies. (2018). School health and safety. Retrieved from https://pids.gov.ph/pids-in-the-news/2482

Philippine Health Research Ethics Board. (2017). National ethical guidelines for health and health-related research 2017. Retrieved from http://www.ethics.healthresearch.ph/index.php/phoca-downloads/category/4neg?download=98:neghhr -2017

Rosales, R. A., Labrague, L. J., \& Rosales, G. L. (2013). Nurses' job satisfaction and burnout: Is there a connection? International Journal of Advanced Nursing Studies 2(1), 1-10. Retrieved from https://pdfs.semanticscholar.org/ 62dd/0b1aec1114a8dd7cbffbd03c7d5ff45f5538.pdf

Saraji, G. N., \& Dargahi, H. (2006). Study of quality of work life (QWL). Iranian Journal of Public Health, 35(3), 8-14. Retrieved from http://ijph.tums.ac.ir/index.php/ijph/article/view/2143

Senate Bill No. 663 (2016). An act assigning one registered nurse for every public school in the Philippines. Retrieved from https://www.senate.gov.ph/lisdata/ 2415120789!.pdf

Smith, S., \& Firmin, M. (2009). School nurse perspectives of their vocational decisions. Journal of Ethnographic \& Qualitative Research, 3, 98-104. Retrieved from https://digitalcommons.cedarville.edu/psychology_publications/104/

Stock, J. L., Larter, N., Kieckehefer, G. M., Thronson, G., \& Maire, J. (2002). Measuring outcomes of school nursing services. Journal of School Nursing, 18(6), 353. doi: 10.1177/10598405020180060801

Suresh, D. (2013). Quality of nursing work life among nurses working in selected government and private hospitals in Thiruvananthapuram (Thesis). Achutha Menon Centre for Health Science Studies Sree Chitra Tirunal Institute for Medical Sciences \& Technology, Kerala, India. Retrieved from http://dspace.sctimst.ac.in/jspui/bitstream/123456789/2265/1/6282.pdf

Thakre, S. B., Thakre, S. S., \& Thakre, S. N. (2017). Quality of work life of nurses working at tertiary health care institution: A cross-sectional study. International Journal of Community Medicine and Public Health, 4(5), 1627-1636. doi: http://dx.doi.org/10.18203/2394-6040.ijcmph20171775

Timossi, L. S., Pedroso, B., Francisco, A. C., \& Pilatti, L. A. (2008). Evaluation of quality of work life: An adaptation from the Walton's model. XIV Conference of Industrial Engineering and Operations Management, Rio de Janiero, Brazil. October 13-16, 2008. Retrieved from http://www.abepro.org.br/biblioteca/enegep2008_TI_ST_072_509_12395.pdf 
Wang, L. Y., Vernon-Smiley, M., Gapinski, M. A., Desisto, M., Maughan, E., \& Sheetz, A. (2014). Cost-benefit study of school nursing services. JAMA Pediatrics, 168(7), 642-648. doi:10.1001/jamapediatrics.2013.5441

Willgerodt, M. A., Brock, D. M., \& Maughan, E. M. (2018). Public school nursing practice in the United States. The Journal of School Nursing, 34(3), 232-244. doi: $10.1177 / 1059840517752456$.

World Medical Association. (2001). World medical association declaration of Helsinki ethical principles for medical research involving human subjects. Bulletin of the World Health Organization, 79(4), 373-374. Retrieved from https://www.who.int/bulletin/archives/79\%284\%29373.pdf

Zborowska-Dulat, A., Uchmanowicz, I., Manulik, E., \& Manulik, S. (2018). Job satisfaction among school nurses. Journal of Education Health and Sports, 8(12), 530-537. Retrieved from http://www.ojs.ukw.edu.pl/index.php/johs/article/view/ 6404 